\title{
Shaping the Culture of Safety through Effective Leadership in Malaysia
}

\author{
Fanny Yam ${ }^{1}$, Chih Siong Wong ${ }^{2}$, Cheah Yuat Hoong ${ }^{3} \&$ Mansoureh Ebrahimi ${ }^{4}$ \\ ${ }^{1}$ Faculty of Chemical and Energy Engineering, UTM \\ ${ }^{2}$ Faculty of Built Environment, UTM \\ ${ }^{3}$ Faculty of Science, UTM \\ ${ }^{4}$ Faculty of Islamic Civilization, UTM \\ Correspondence: Mansoureh Ebrahimi, Faculty of Islamic Civilization, UTM. E-mail: suriebrahimi@gmail.com
}

Received: March 5, 2016

Accepted: March 27, 2017

Online Published: May 10, 2017

doi:10.5539/ach.v9n2p1

URL: https://doi.org/10.5539/ach.v9n2p1

\begin{abstract}
Despite the enforcement of safety protocols, several workplaces and organizations still face accidents in Malaysia. SOSCO reported $>34,000$ workplace related accidents in 2012, 983 of which were fatal. Leadership is important when creating a culture that supports and promotes health and safety. Management and Team leaders are vital in inspiring workers to higher levels of safety consciousness and productivity, which means they must personally apply good leadership attributions daily. A 'Safety Culture' describes a safety management style in the workplace that reflects attitudes, beliefs, perceptions and values shared by all workers with regard to safety. The objectives of this study include raising the awareness among leaders in the workplace of their role and responsibility in the mitigation and construction of a safety culture that approaches zero incidents in the workplace. The methodology used in this paper includes a qualitative literature research on safety culture and leadership in addition to a quantitative survey that focused on safety culture at two Malaysian universities. This research thus provides an in-depth analysis and platform for organizations to identify areas of weakness and concern and can lead to further research that builds on existing systems to strengthen safety culture awareness and praxis.
\end{abstract}

Keywords: safety culture, leadership

\section{Introduction}

Regulations on public safety can be traced to King Hammurabi of Babylon in 1800 BC. The Hammurabi Code of Law (Regulations 229-238) is inscribed on stone tablets. They state that any house builder who is guilty of causing the death of another person is punishable by death (King, 2008). Safety regulations have since evolved and most of the beneficial regulatory changes were made after the post-industrial revolution, to include the Safety \& Health Act, Factory and Machinery Act, etc. However, these still need to be strengthened and improved, not only in industrial sectors but also extended to other workplaces such as institutions and schools. The Safety Culture in the latter sectors seems to be far more lacking in oversight compared to the industrial sector.

'Culture of safety' reflects attitudes as well as beliefs, perceptions and values of the people responsible for implementation. Leadership is very crucial to the provision and guidance of an organized safety management system, as documented by the American National Standards Institute (ANSI) and the Occupational Safety and Health Administration (OSHA). Both ANSI and OSHA have identified leadership as the core component of effective safety management (Dunlap, 2011), and both groups agree that good leadership leads to good safety performance. OSHA has outlined the following components of a safety management system:

1) Employee involvement: Involve employees and gain their commitment to increase the quality of workplace safety efforts (Dunlap, 2011; Malaysia, 1994).

2) Accountability: Establish performance standards, provide resources, design measurement systems, apply consequences, implement all of these at all levels within the organization as a system of accountability (Dunlap, 2011; Malaysia, 1994).

3) Development of a safety culture: Safety is identified as the need to have elements of a safety culture (Dunlap, 2011).

4) Management engagement: Leaders must focus on multiple areas for which they are directly responsible. Their engagement is critical to the success of injury reduction efforts (Dunlap, 2011). 
These components and strategic directives provide resources and constantly emphasize the need to reinforce the importance of safety. Hence, ineffective leadership of safety culture is at the root of failure (Cooper, 2015).

The Department of Safety and Health Statistics reported $\sim 3000$ cases of manufacturing accidents in 2015, ranging from quarrying to business and finance sectors. However, incidents for institutions and schools were not listed as a distinct category (DOSH, 2015). On the other hand, numerous safety accidents and incidents are reported from time to time in the newspaper, including, for example, students being struck by vehicles, ceiling tiles falling, exercise/sports injuries, lab accidents, etc., all of which raise the alarm for the importance of safety culture in institutions and schools; thus indicating the need for more attention.

The need to understand institutional safety culture praxis with respect to risk management, accident prevention and emergency protocols prompted the authors to conduct surveys at two institutions. Our main objective was to identify a degree of understanding for leadership's role in strengthening safety praxis and to provide suggestions for improvement.

\section{Literature Review}

\subsection{Safety Culture and Statistic}

\subsubsection{Safety Culture}

Safety Culture refers to attitudes, beliefs, perceptions, values, competencies and behaviors of people within an organization regarding matters of safety (IOSH, 2015). It is incumbent on everyone to take preventive measures that enhance an organization's safety consciousness. This requires trust, clear communications and everyone's participation.

\subsubsection{Safety Statistic of Malaysia}

Work related accidents in the industry sector remain a major issue with thousands of reportable accident notifications received by SOCSO. Although a trend towards reduction has been observed over the years, the number of accidents remains significant with $>34,000$ industrial incidents reported in 2012 - 983 of which were fatal (See: Figure 1).

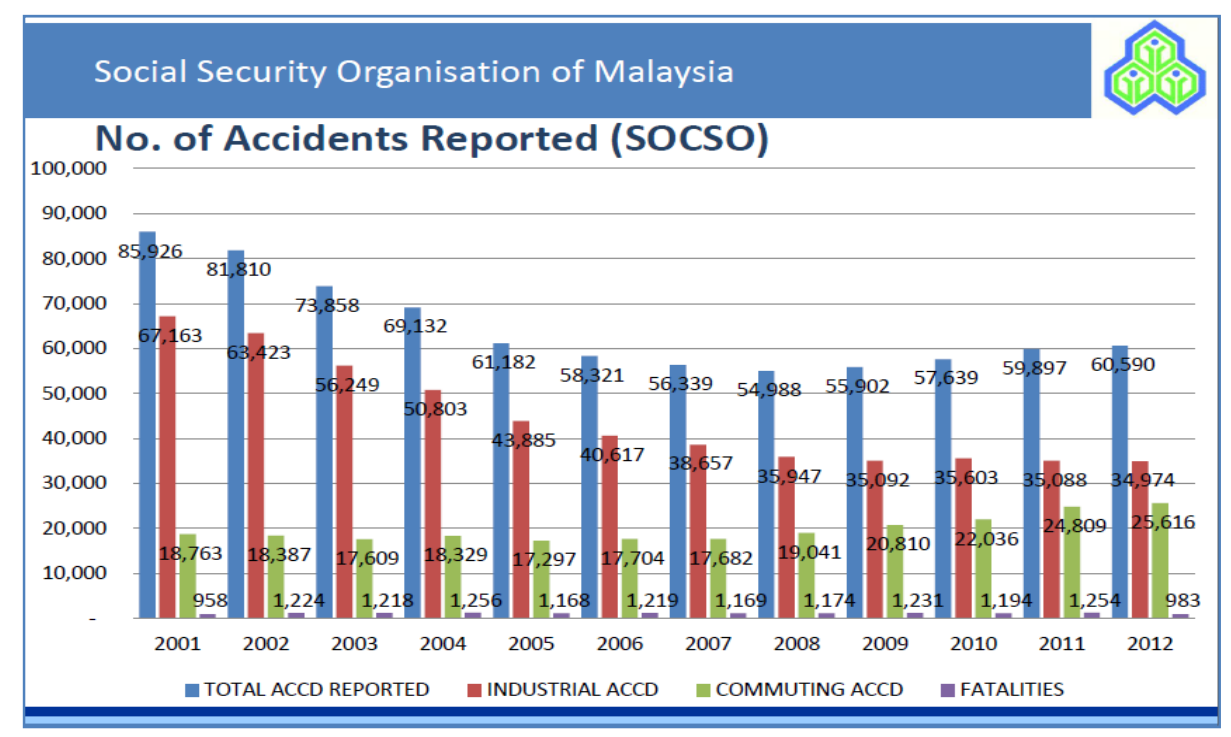

Figure 1. Occupational Injury Statistic Published by SOCSO

The Department of Safety and Health (DOSH) reported 3,345 workplace accidents in 2015 (See: Fig. 2); most occurring in the manufacturing sector followed by agriculture and construction (DOSH, 2015). Data for institutes/schools remains unknown.

The New Straits Times reported 18 accidents and one fatality in schools, and 10 accidents and one fatality in institutions of higher learning between 2012 and 2015. They also reported the following information provided by the Department of Occupational Safety and Health (NST, 2016). 


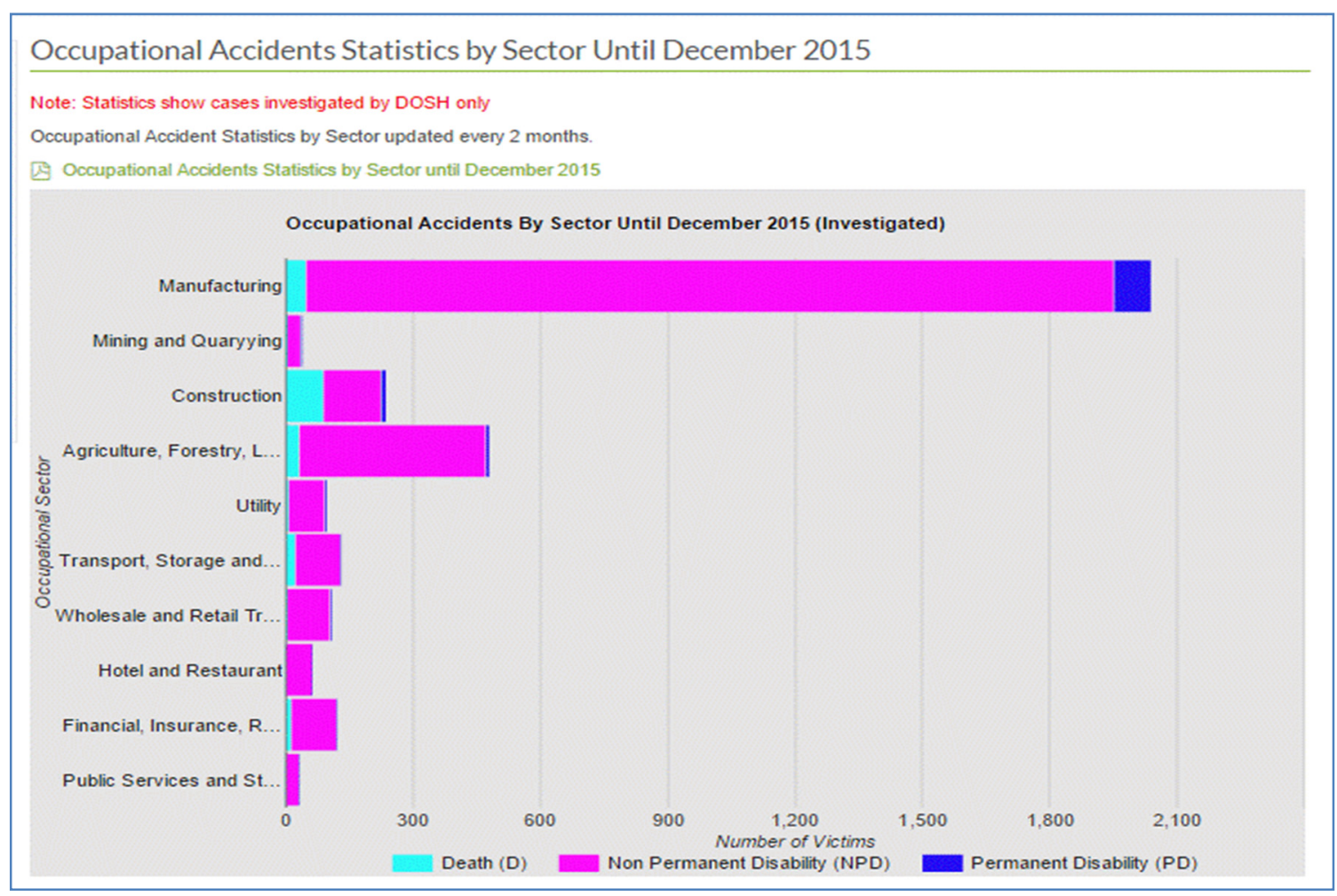

Figure 2. Investigated Incidents Reported by Department of Occupational Safety and Health (DOSH)

\subsection{Leadership}

Table 1. Leadership Behaviours for Safety Comparison (Source: Flin \& Yule, 2004)

\begin{tabular}{|c|c|c|}
\hline & Transactional behaviours & Transformational behaviours \\
\hline Supervisors & $\begin{array}{l}\text { Monitoring and reinforcing workers' safe } \\
\text { behaviours } \\
\text { Participating in workforce safely activities } \\
\text { (can also be transformational) }\end{array}$ & $\begin{array}{l}\text { Being supportive of safely } \\
\text { initiatives } \\
\text { Encouraging employee involvement in } \\
\text { safety initiatives }\end{array}$ \\
\hline Middle managers & $\begin{array}{l}\text { Becoming involved in safely initiatives } \\
\text { (can also be transformational) }\end{array}$ & $\begin{array}{l}\text { Emphasising safety over productivity } \\
\text { Adopting a decentralised style } \\
\text { Relaying the corporate vision for safely to } \\
\text { supervisors }\end{array}$ \\
\hline Senior managers & $\begin{array}{l}\text { Ensuring compliance with regulatory } \\
\text { requirements } \\
\text { Providing resources for a comprehensive } \\
\text { safely programme }\end{array}$ & $\begin{array}{l}\text { Demonstrating visible and consistent } \\
\text { commitment to safety } \\
\text { Showing concern for people } \\
\text { Encouraging participatory styles in } \\
\text { middle managers and supervisors } \\
\text { Giving time for safety }\end{array}$ \\
\hline
\end{tabular}

Leadership's important role in effective safety management in industrial sectors has been the focus of much research for several years. However, very few researchers have undertaken similar work in institutional sectors. A selective review of the industrial safety literature on leadership in health care was done that revealed the importance of a participative, transformational approach to safety praxis at all management levels (See: Table 1). Transactional approaches with attention to monitoring and the reinforcement of workers' safety behavior have been correlated with effective supervision. Middle management's involvement in safety fosters open communication and ensures compliance with safety protocols. Moreover, supervisors should be allowed a degree of autonomy for safety initiatives. Nonetheless, senior managers hold primary sway over an organization's safety culture.

The relationship between transactional and transformational leadership behavior and performance is shown below: 


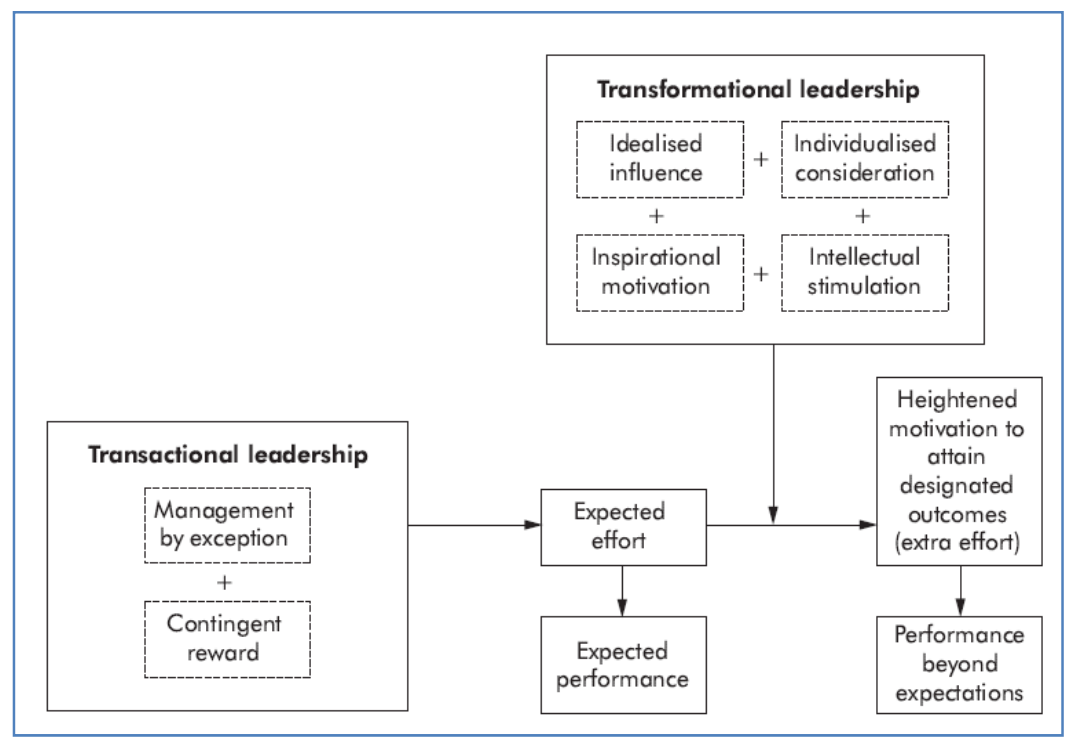

Figure 3. Mutual Augmentation of Transformational On Transactional Leadership Styles (Source: Flin \& Yule, 2004).

\section{$\underline{\text { Supervisors }}$}

First-line managers, supervisors, foremen and team leaders support industry. Supervisors have the primary responsibilities of task achievement and the maintenance of team wellbeing. Moreover, the structuring, coordination and facilitation of work activities involves transactional and transformational leadership approaches relevant to this level of management.

\section{Middle managers}

In terms of direct influence, middle management demonstrates commitment to safety by prioritizing safety over productivity when these objectives conflict in favor of the latter. Thus, they become involved in safety initiatives by reinforcing the activities of their frontline staff. Participative transformational leadership styles appear more effective when managing safety protocols. Middle managers must also determine how the corporate vision for safety, as espoused by senior managers, is relayed to frontline supervisors.

\section{$\underline{\text { Senior managers }}$}

Most senior managers (e.g., CEO or Director of Operations) are generally situated far from operational activities, since their responsibilities are strategic and include long range planning, etc. However, they remain ultimately accountable for their organization's safety performance with increasing legal consequences for proven failures.

The higher individuals are within an organization, the greater their potential to influence organizational outcomes. Decisions made at senior levels affect priorities as well as attitudes and the behaviors of managers and employees right on down the organizational hierarchy and are critical drivers for first-line managers, especially with regard to competing values of safety vs. productivity.

\subsection{Research Methodology}

As confirmed by Guldenmund (2000), the Glendon \& Stanton (2000) and Collins \& Gadd (2002) survey questionnaires are major assessment devices when focused on safety climate and safety culture. 'Safety Culture' differs from 'Safety Climate'. The former concerns long-term behavior of people who hold certain beliefs, values, competencies and attitudes. 'Safety Climate' is a mere snapshot at a particular point in time (Flin et al. 2000). However, survey questionnaires are not the only method available to us. Moreover, in contrast to quantitative contributions, both safety culture and climate can also be measured qualitatively (Cooper, 2000). Such methods normally involve direct contact and interaction with the individuals involved. This could entail a one-to-one encounter or a group setting via interviews, focus groups, observation, ethnography, and so on. Nonetheless, Cooper (2000) recommended a holistic approach that combined qualitative and quantitative approaches as effective assessment tools. One such example is the triangulated methodology proposed by Glendon \& Stantion (2000) that analyses multi-levels of a safety culture within a particular organization. This is accomplished by a series of combined methods using questionnaire surveys, audits, interviews, etc., that enable a well-rounded 
inquiry and analysis. Hence, a variety of instruments, both qualitative and quantitative or in combination, are in use for safety climate and culture evaluations (O’Connor et al. 2011; Edwards et al. 2013).

Cooper (2000) identified three dimensions that describe an organization's state and attitude toward safety: situational, psychological and behavioral. The situational dimension captures data related to management policies, procedures, systems and so on. Psychological aspects concern individual opinions towards matters of safety and health; the behavioral domain concentrates on related human activity. Glendon \& Stanton (2000) recommended Litherland's suggestion (1997) of six categories to assess the field of safety. These included 'management's commitments and attitudes', followed by 'safety training', 'safety procedures', 'work hazards', and the 'overall perception of safety risk's as well as 'staff involvement in matters pertaining to safety'.

Due to safety culture's complexity, no universal tool is available to measure all facets. When searching for effective measurement tools to assess all dimensions, Guldenmund (2010) endorsed three meaningful approaches; Academic, Analytical and Pragmatic, each with different techniques and tools. The Academic approach primarily concentrates on past events and organizational history, indicating that current circumstances are consequent to previous events and conditions. Hence, it is more orientated towards field research and is naturally qualitative; thus capturing data by interview, observation, literature review, document analysis, and so forth. The Analytical approach concerns an organization's current state. Current organizational situations are normally assessed by survey questionnaires and rating scales that are typically self-administered. Therefore, answers found by the Analytical approach can be explained within the context of the Academic approach. The Pragmatic approach focuses on an organization's future and is based on expert opinion, as organizational processes and structure are the main foci of study. The interrelationship between these factors influences the shaping of an organization's general culture, which consequently and directly affects the behavior of all involved parties. Hence, this approach emphasizes required changes in the current culture for the betterment of an organization's future. Overall, safety culture should be investigated and analyzed within a specific context by using relevant validated data, regardless of methodology and selected instruments.

\section{Survey Method}

We conducted pilot surveys on the 'safety culture' of two private Malaysian universities, one in central Sarawak, East Malaysia, and the other in Kuala Lumpur, West Malaysia. We followed Hudson's (2007) recommendations and chose a simple short format to allow quick comprehension and obtain accurate responses. The survey instrument combined and incorporated an altered variant of the 'Safety Culture Survey Questionnaire' (Lyons, 2016), and the 'Sample Safety Perception Survey Form and Questions' (Roughton \& Mercurio, 2002, pp. 469473), and the 'Safety Program Evaluation Form' (Roughton \& Mercurio, 2002, pp. 425-468). Substantial amendments and adjustments were made because these instruments were not intended for use in higher education institutions. Consequently, the questionnaire contained 24 questions that covered six different categories: Training and Education, Safe Work Procedures, Consultation, Safety Reporting, Management Commitment and Leadership, and Injury Management.

The Training and Education portion queried the provision of well-organized safety training program for faculty members and the periodic execution of emergency plans. Queries regarding Safe Work Procedures concentrated on the existence of well-written safe work protocols. The Consultation portion aimed to capture feedback on communications between top management and all related parties. Safety Reporting focused on reporting protocols. Management Commitment and Leadership queries investigated the level of effort exerted by management in the promotion of a safety culture through leadership and example. The Injury Management component queried the availability of information as well as the reporting of injuries, injury management personnel and appropriate medical care.

Each category was accommodated by four questions and paraphrased to better reflect descriptors and situations in Malaysian higher education institutions. For instance, 'management' replaced the word 'company' and 'university' replaced the word 'workplace'. Several demographic questions were added to the mix to acquire data related to respondents' university location, gender, category (student, academic, non-academic), and the length of time attached to the university. We developed a precise and concise survey format because most questionnaires on safety culture were too lengthy, as indicated by Blewett et al. (2012). We oppose lengthy surveys due to the fact that respondents tend to lose focus. Although a detailed questionnaire appears attractive, it may not capture data as accurately as a more concise format. To forestall respondent fatigue, the questionnaire comprised only one page and was very easy on comprehension and compliance. Respondents took five minutes or less, on average, to complete it. Similar to Lyons's approach (2016), our survey questions mined respondent knowledge and experience rather than insight, attitude or opinion. Nevertheless, the 'Management Commitment and Leadership' segment focused more on perception than experience. 
Response options were based on closed-ended questions that measured how strongly respondents agreed or disagreed with a given statement (Likert Scale). Respondents chose one of four options that described their experience. Significant non-demographic queries had four response choices: 1, Strongly Disagree: 2, Disagree; 3 , Agree; and 4, Strongly Agree. There were no neutral or diplomatic response choices, e.g., 'none of the above' or 'neither disagree or agree', because these options take a middle path that offers less information and more confusion (Carroll, 1998; Kines et al. 2011).

Numerical values for specific responses were calculated in three steps to compute scaled scores between 1 and 4 . First we determined an individual value for each respondent. Second, we summed all individual values. We then divided respondent sums by the total number of respondents, thus providing a scaled score for each question. Category scores were computed by adding all individual scale scores for questions within a specific category divided by the total number of questions. Numerical interpretations for each survey item's scaled score were assigned as follows: $\mathbf{3} \mathbf{3 . 5}=$ little need to improve; $\mathbf{3 . 0}-\mathbf{3 . 4 9}=$ slight need to improve; $\mathbf{2 . 5}-\mathbf{2 . 9 9}=$ need to improve; $\mathbf{\leq 2 . 5}$ = major improvement required.

To assure similar experiences for all respondents, comparable faculty/staff members and students from each university were recognized as probable participants. A total of 539 respondents from the 'Built Environment' in East Malaysia, and 514 from 'Foundation Studies' in West Malaysia were chosen. The decision to choose only a few faculty members seemed sensible based on the assumption they were homogeneously culturally oriented with low-risk safety profiles. Convenient sampling was used for the survey. Respondents were given a hand-distributed questionnaire seeking participation. The completed questionnaire was collected 'on the spot', which only took five minutes on average.

\section{Results and Discussion}

\subsection{Pilot Study 1: East Malaysia}

Survey invitations were distributed by hand during the first week of October 2016, and we received immediate feedback from 216 respondents (40\%) of 539 people from the Faculty of Built Environment. Higher numbers of respondents indicate a more meaningful analysis that generally represents the opinion of the population. The ratio of male to female was $\sim 1(51: 49)$. The majority of respondents were students $(82 \%)$, and the remaining $18 \%$ were staff members, both academic and not. Forty-four per cent (44\%) of respondents had spent one to two years at the university; $36 \%$ more than 2 years, and $20 \%$ had been at the institution less than one year.

Table 2 summarizes responses from 24 questions. 'Agree' and 'Strongly Agree' answers (values of 3 and 4) were combined into one 'Agree' column. Likewise, 'Disagree' and 'Strongly Disagree' (values of 2 and 1) were merged into one 'Disagree' column.

Table 2. Pilot Study 1 - Summary of Responses

\begin{tabular}{lccc}
\hline Category & Number of Questions & Number of Agree & Number of Disagree \\
\hline Training and Education & 4 & 3 & 1 \\
Safe Work Procedures & 4 & 4 & 0 \\
Consultation & 4 & 2 & 2 \\
Reporting Safety & 4 & 4 & 0 \\
Management Commitment and Leadership & 4 & 4 & 0 \\
Injury Management & 4 & 3 & 1 \\
Total & 24 & 20 & 4 \\
\hline
\end{tabular}

Answers for 4 of 24 queries were $\geq 50 \%$ 'disagree' for 'Training and Education' and 'Injury Management'. Two 'Consultation' questions also obtained 'disagree'. Hence, 20 of 24 queries (83\%) received more positive feedback; thus depicting a positive safety culture at this university and awareness of safety issues, although intensity required further scrutiny.

Table 3 shows questions where $\geq 50 \%$ respondents disagreed. Preliminary analysis obtained a clear picture that these areas were below standard and require improvements. 
Table 3. Pilot Study 1 - Disagree Responses

\begin{tabular}{ll}
\hline Category & Questions with 50\% 'Disagree' Reponses \\
\hline Training and Education & Q 4. We periodically practice implementation of emergency plans. \\
& Q 10. We know who our safety representative or safety committee member is. \\
Consultation & Q 12. Safety managers communicate with us and listen to us about health and safety. \\
Injury Management & Q 21. There is information about injury management on display near our work area. \\
\hline
\end{tabular}

The calculation of scaled scores for survey questions is essential when drawing a more detailed perspective from preliminary analysis. Table 4 shows that none of the questions scored more than 3.0 and that the majority of scores (79\%) ranged between 2.5 to 2.99 with the remaining 5 questions $(21 \%)$ scoring $<2.5$.

Table 4. Pilot Study 1 - Scaled Score Classification

\begin{tabular}{clcc}
\hline Scaled Score Classification & \multicolumn{1}{c}{ Status } & Number of Questions & \% \\
\hline$\geq 3.5$ & Little need to improve & 0 & 0 \\
$3.0-3.49$ & Slight need to improve & 0 & 0 \\
$2.5-2.99$ & Need to improve & 19 & $79.17 \%$ \\
$<2.5$ & Substantial need to improve & 5 & $20.83 \%$ \\
& Total & 24 & $100.00 \%$ \\
\hline
\end{tabular}

Table 5 allows the conclusion that all six categories measured fell short of acceptable standards. Not one category scored $\geq 3.0$, and Consultation scored $<2.5$.

Table 5. Pilot Study 1 - Scaled Scores for Safety Culture Category

\begin{tabular}{lc}
\hline Category & Scaled Score \\
\hline Training and Education & 2.53 \\
Safe Work Procedures & 2.73 \\
Consultation & 2.49 \\
Reporting Safety & 2.55 \\
Management Commitment and Leadership & 2.71 \\
Injury Management & 2.60 \\
\hline
\end{tabular}

Tables 4 and 5 strongly imply that a prominent safety culture does not exist. Five statements scored $<2.5$ (See: Table 6), indicating a remarkable lack of certain safety standards that require serious remedy.

Table 6. Pilot Study 1 - Questions with Scaled Scores $<2.5$

\begin{tabular}{|c|c|c|}
\hline Category & Survey Question & $\begin{array}{l}\text { Scale } \\
\text { Score }\end{array}$ \\
\hline Training and Education & Q 4. We periodically practice implementation of emergency plans. & 2.38 \\
\hline Safe Work Procedures & Nil & - \\
\hline \multirow{3}{*}{ Consultation } & $\begin{array}{l}\text { Q 9. We have a communication system in place with safety managers/officers about } \\
\text { safety issues. }\end{array}$ & 2.47 \\
\hline & Q 10. We know who our safety representative or safety committee member is. & 2.44 \\
\hline & Q 12. Safety managers communicate with us and listen to us about health and safety. & 2.47 \\
\hline Reporting Safety & Nil & - \\
\hline $\begin{array}{l}\text { Management Commitment and } \\
\text { Leadership }\end{array}$ & Nil & - \\
\hline Injury Management & Q 21. There is information about injury management on display near our work area. & 2.49 \\
\hline
\end{tabular}

Staff and students believe they need more training and education in the practice of emergency plans such as fire drills, indicating concern about evacuation in the event of a fire or other emergency. Such awareness is important in today's chaotic age because we are vulnerable to all sorts of emergencies, including terrorist attacks. 
'Consultation' drew a lower group scaled score than others, with 3 of 4 respondents scoring no more than 2.5. In this context, 'Consultation' does not mean informing faculty members of health and safety matters only, but also concerns communications between management teams and faculty members. Hence, management should not be limited to the role of merely informing or giving instructions on safety matters, as all faculty members should be given reasonable opportunity to express opinions in any decision making process. Good leadership must enable everyone in the faculty clear instructions regarding who, where, when and how to communicate on matters of safety and health.

Leaving people in the dark, especially when related to safety is not a good management practice, as there is nothing more important than a culture that creates and promotes a safe environment for everyone's benefit. Table 6 also indicates that relevant information regarding injury management is handy for faculty members. This information should be noticeably displayed at work areas and easily accessible to everyone. Although the cited areas require substantial attention, more specifically at the faculty level, other aspects related to 'Safe Work Procedures', 'Safety Reporting', and 'Management Commitment and Leadership' also require serious attention.

\subsection{Pilot Study 2: West Malaysia}

The second pilot survey in West Malaysia took place during the second week of October 2016 and took a week to complete. Our hand survey invitation received 147 responses from a targeted population of 514 people at Foundation Studies (29\%). The majority of respondents were female (67\%), 33\% were males. A minority were staff (12\%), $88 \%$ were students; $44 \%$ had spent one to two years in this university, and $36 \%$ more than 2 years. Table 7 summarizes of responses to 24 questions using the same merger method as in the first pilot study.

Table 7. Pilot Study 2 - Response Summary

\begin{tabular}{lccc}
\hline Category & Number of Questions & Number of Agree & Number of Disagree \\
\hline Training and Education & 4 & 1 & 3 \\
Safe Work Procedures & 4 & 4 & 0 \\
Consultation & 4 & 2 & 2 \\
Reporting Safety & 4 & 3 & 1 \\
Management Commitment and Leadership & 4 & 4 & 0 \\
Injury Management & 4 & 3 & 1 \\
Total & 24 & 17 & 7 \\
\hline
\end{tabular}

We received 7 'disagree' responses (50\%), 3 more than our first pilot study, and of which four were the same (See: Table 4.7), pertaining to 'Training and Education', questions 10 and 12 on 'Consultation', and question 21 on 'Injury Management'. For this survey, respondents provided 2 more 'disagree' responses for 'Training and Education' (questions 1 and 2). Another 'disagree' response came from question 13 on 'Safety Reporting'. Table 8 shows that staff and students reported results that were far from satisfactory.

Table 8. Pilot Study 2 - 'Disagree' Responses

\begin{tabular}{ll}
\hline Category & Questions with 50\% 'Disagree' Reponses \\
\hline \multirow{3}{*}{ Training and Education } & Q 1. An organized safety training program exists. \\
& Q 2. We receive safety training. \\
& Q 4. We periodically practice implementation of emergency plans. \\
& Q 10. We know who our safety representative or safety committee member is. \\
Consultation & Q 12. Safety managers communicate with us and listen to us about health and safety. \\
Reporting Safety & Q 13. We have safety reporting procedures (for incidents and issues) and we use them. \\
Injury Management & Q 21. There is information about injury management on display near our work area. \\
\hline
\end{tabular}

Although only 7 of 24 questions (29\%) received negative feedback, survey results suggested that the concept of 'safety culture' had yet to attain an acceptable level of awareness. For additional insight, scaled scores are better benchmarks for safety culture awareness. As in the first pilot study, not one question received $>3.0$ (See: Table 9) and $63 \%$ of responses qualified as 'need for improvement', while $38 \%$ called for substantial improvement. 
Table 9. Pilot Study 2 - Scaled Score Classification

\begin{tabular}{clcc}
\hline Scaled Score Classification & \multicolumn{1}{c}{ Status } & Number of Questions & \% \\
\hline$\geq 3.5$ & little need to improve & 0 & 0 \\
$3.0-3.49$ & slight need to improve & 0 & 0 \\
$2.5-2.99$ & need to improve & 15 & $62.50 \%$ \\
$<2.5$ & substantial need to improve & 9 & $37.50 \%$ \\
& Total & 24 & $100.00 \%$ \\
\hline
\end{tabular}

Table 10 shows that all six categories require improvement. 'Training and Education' and 'Consultation' were lowest in terms of category scaled scores, indicating a need for special emphasis to heighten standards.

Table 10. Pilot Study 2 - Category Scaled Scores

\begin{tabular}{lc}
\hline Category & Scaled Score \\
\hline Training and Education & 2.32 \\
Safe Work Procedures & 2.72 \\
Consultation & 2.43 \\
Reporting Safety & 2.58 \\
Management Commitment and Leadership & 2.68 \\
Injury Management & 2.68 \\
\hline
\end{tabular}

Tables 9 and 10 clearly indicate that safety culture standards in this institution are far from acceptable. Table 11 shows specific areas that require remediation.

Table 11. Pilot Study 2 - Questions with Scaled Scores $<2.5$

\begin{tabular}{|c|c|c|}
\hline Category & Survey Question & $\begin{array}{l}\text { Scaled } \\
\text { Score }\end{array}$ \\
\hline \multirow{4}{*}{ Training and Education } & Q1. An organized safety training program exists. & 2.35 \\
\hline & Q2. We receive safety training. & 2.25 \\
\hline & Q3. We understand the university's safety system. & 2.45 \\
\hline & Q4. We periodically practice the implementation of emergency plans. & 2.22 \\
\hline \multirow[t]{2}{*}{ Safe Work Procedures } & Nil & \\
\hline & $\begin{array}{l}\text { Q9. We have means to communicate with safety managers/officers about safety } \\
\text { issues. }\end{array}$ & 2.46 \\
\hline \multirow[t]{2}{*}{ Consultation } & Q10. We know who our safety representative or safety committee member is. & 2.23 \\
\hline & $\begin{array}{l}\text { Q12. Safety managers communicate with us and listen to us about health and } \\
\text { safety matters. }\end{array}$ & 2.40 \\
\hline Reporting Safety & $\begin{array}{l}\text { Q13. We have safety reporting procedures (for incidents and issues) and we use } \\
\text { them. }\end{array}$ & 2.47 \\
\hline $\begin{array}{l}\text { Management Commitment and } \\
\text { Leadership }\end{array}$ & Nil & - \\
\hline Injury Management & $\begin{array}{l}\text { Q21. There is information about injury management on display near our work } \\
\text { area. }\end{array}$ & 2.41 \\
\hline
\end{tabular}

Table 10 indicates that respondents from this university felt a need for more safety 'Training and Education' (staff and students). Each of 4 questions on 'Training and Education' scored $<2.5(\sim 2.32)$, which indicates an urgent need for management to organize a series of safety-training programs. This includes not only informative sessions but also practice such as fire drills, etc., and at a sufficient level to increase effective safety responsiveness during emergency circumstances. 'Consultation' is another category that requires serious consideration, as the 'lack of two-way communication' was the main offender, having received a low score. Existing staff and students have the right to become involved in a safety committee through a safety representative and also require a channel to voice views and ideas about safety and health issues. More importantly, management should listen openly and accept reasonable and constructive suggestions and comments. Moreover, 'safety reporting' procedures must be properly 
in place and sufficiently effective for use by all faculty members. In addition, an appropriate display of adequate information related to injury management is imperative, especially near work areas with high risks. People need to know how to respond properly and have correct information within their reach.

The remaining 15 questions that fell within a scaled score range of 2.5 to 2.99 should not being taken lightly. These areas might not need major improvement but are surely in need of certain enhancements.

\subsection{Comparison of East and West Pilot Studies}

Comparing both universities based on these studies might provide a valid analysis. This is especially true as both samples derive from different faculties, one being 'Built Environment' and the other 'Foundation Studies'. However, findings remain noteworthy as they provide a meaningful overall impression on the extant safety culture of higher institutions within the Malaysia context.

Table 12. Comparison - Number of Questions for Scaled-Score Classification

\begin{tabular}{llcccc}
\hline \multirow{2}{*}{ Scaled Score Classification } & \multirow{2}{*}{ Status } & Pilot Study 1 & \multicolumn{2}{c}{ Pilot Study 2 } \\
\cline { 2 - 5 } & & Number of Questions & $\mathbf{\%}$ & Number of Questions & $\mathbf{\%}$ \\
\hline 3.5 & Little need to improve & 0 & 0 & 0 & 0 \\
$3.0-3.49$ & Slight need to improve & 0 & 0 & 0 & 0 \\
$2.5-2.99$ & Need to improve & 19 & $79.16 \%$ & 15 & $62.50 \%$ \\
$<2.5$ & Substantial need to improve & 5 & $20.83 \%$ & 9 & $37.50 \%$ \\
& Total & 24 & $100.00 \%$ & 24 & $100.00 \%$ \\
\hline
\end{tabular}

Table 13. Comparison - Scaled Scores for Safety Culture

\begin{tabular}{lcc}
\hline \multirow{2}{*}{ Category } & \multicolumn{2}{c}{ Scale Score } \\
\cline { 2 - 3 } & Pilot Study 1 & Pilot Study 2 \\
\hline Training and Education & 2.53 & 2.32 \\
Safe Work Procedures & 2.73 & 2.72 \\
Consultation & 2.49 & 2.43 \\
Reporting Safety & 2.55 & 2.58 \\
Management Commitment and Leadership & 2.71 & 2.68 \\
Injury Management & 2.60 & 2.68 \\
\hline
\end{tabular}

Referring to Tables 12 and 13, both universities failed to register any scaled score $>3.0$. This striking similarity is an obvious clue that safety culture does exist in higher institutions although its competence level is inadequate. All six categories mentioned in Table 13 scored $<3.0$. Pilot study 1 shows one category at $<2.5$, while Pilot 2 shows 2 categories at $<2.5$. Converting the scaled score scheme of these pilot studies to an academic grading system reflects the level of safety culture. Assuming a score $<2.5$ represents 'fail', then scores from 2.5-2.99 represent 'pass', and from 3.0-3.49 represent 'credit', and $>3.5$ represent 'distinction'. Performances for 'safety culture' in Table 13 indicate very poor results with a majority of categories only just reaching a 'pass'. Unfortunately, some categories failed, and overall questions (Table 12) and categories (Table 13) fell under 3.0, indicating discouraging results. Reaching the state of a strong safety culture definitely has far to go. Nonetheless, no evidence exists showing a lack of leadership commitment by management teams of either institution, as depicted in 'Management Commitment and Leadership' (Tables 13 and 14).

However, their efforts appear weak to inadequate at a mere passing level and likely correlates with the category of 'Consultation', for which both institutions registered a 'fail' (Table 13).

Table 14. Comparison - Questions for Management Commitment and Leadership

\begin{tabular}{lcc}
\hline \multirow{2}{*}{ Management Commitment and Leadership } & \multicolumn{2}{c}{ Scale Score } \\
\cline { 2 - 3 } & Pilot Study $\mathbf{1}$ & Pilot Study 2 \\
\hline Q 17. A written policy that sets a high priority for safety exists. & 2.67 & 2.54 \\
Q 18. Management always gets involved in safety issues. & 2.68 & 2.63 \\
Q 19. Management supports safety rules and regulations. & 2.82 & 2.89 \\
Q 20. Management always means what they say and do what they say, in safety matters. & 2.69 & 2.65 \\
\hline
\end{tabular}


Table 15. Comparison - Survey Questions for Consultation

\begin{tabular}{|c|c|c|}
\hline \multirow{2}{*}{ Consultation } & \multicolumn{2}{|c|}{ Scale Score } \\
\hline & Pilot Study 1 & Pilot Study 2 \\
\hline Q 9. We have means of communications with safety managers/officers regarding safety issues. & 2.47 & 2.46 \\
\hline Q 10. We know who our safety representative or safety committee member is. & 2.44 & 2.23 \\
\hline Q 11. Management sometimes takes notice of what we say about safety. & 2.58 & 2.61 \\
\hline Q 12. Safety managers communicate with us and listen to us about health and safety. & 2.47 & 2.40 \\
\hline
\end{tabular}

Leadership (Table 15) is strongly positioned within a top-down management approach that prefers a compliance mindset rather than a more open consultation style. Both institutions failed 3 of 4 questions (questions 9, 10 and 12) in 'Consultation' and the remaining question (11) barely passed. Top management with an autocratic leadership prefers followers and is reluctant to engage in two-way communications that assist mutual understanding regarding safety and health matters. This matter-of-fact hinders any advance of existing a safety culture to the next level. As pointed out by Lyons (2016), research findings (Christian et al. 2009) indicate that safety culture inclines towards staff involvement rather than any mere taking of orders from top management. Although financial constraints or manpower issues from management's perspective can and do exist, safety matters cannot be swept under the carpet. There is no doubt that every aspect of a safety culture for both institutions requires attention for further improvement. Indeed, there is much room for improvement by management to enhance the existing safety culture by providing Safety Training and Education, and by enforcing better Safety Reporting Procedures as well as Safe Work Procedures and Injury Management Systems. Much work is yet to be done by management, although some might argue the contrary that there is little to worry about because Malaysia remains a safe haven. They may cite incidents like the November 2015 Paris attacks (Bronstein et al., 2016), or the 2012 Aurora shooting in a movie theatre (Pearson, 2012; Collman, 2015), saying these are rare cases that only happen in the west. Such optimism is pleasant but safety matters should not be overlooked when one considers the following instances:

(i) Movida night club bombing by the Islamic State (IS) on 28 June 2016 in Kuala Lumpur (Kumar, 2016b; Mohd, 2016; Ramendran, 2016; Lourdes 2016);

(ii) The bomb threat at Bursa Malaysia security office on 30 September 2016 in Kuala Lumpur (Lim, 2016; Song, 2016);

(iii) The bomb threat at SEGI University on 22 January 2016 in Kuala Lumpur (Kumar, 2016a; Ahmad, 2016; Hamudin, 2016);

(iv) The bomb scare at First City University College Bandar Utama on 10 October 2016 in Kuala Lumpur (Silva, 2016; Lee, 2016);

(v) The recent fire at the Sultanah Aminah Hospital on 15 October 2016 in Johor Bahru (Said and Othman, 2016; Othman, 2016).

We must ask if we are ready for such emergencies, especially in this chaotic age. Do we know how to react to these types of emergences? Do we have emergency plans in place to counter such situations? These questions can go on and on, but one thing is certain: the concept of a 'safety culture' has yet to mature as a priority in Malaysia. Abraham Maslow wrote that 'safety needs are a second priority for mankind' in his Five-Stage Hierarchy of Needs in 1943 (Figure 4). Even so, management often tends to ignore safety like the proverbial ostrich with its head in the sand. But we must bear in mind that emergencies come like a thief without bell ringing or prior appointment.

Prevention is better than cure. Hence, management should lead to move the concept of safety culture forward. Knee-jerk responses in matters of safety must to be avoided. Management bears the responsibility to prepare all parties for a culture of safety praxis as a number one priority. Moreover, all parties should extend their full cooperation with management teams in the implementation of safety practices. Roughton and Mercurio (2002) highlighted the importance of management's leadership as the 'chief motivating force' that moves everyone towards a successful safety culture (Figure 5). Lyons (2016) pointed out that the safety culture of Universities in New South Wales Australia was a 'work in progress'. Similarly, our pilot surveys of both Malaysian institutions clearly indicate that the development of safety culture remains in its infancy (See: Figure 5). Although Figure 5 depicts a non-higher institutional setting, its definitions are relevant and applicable. The second picture sums the important leadership role that is played by management in higher institutions to promote safety culture. Once achieved, the level of safety awareness will definitely increase and unnecessary expenses for safety hazards will decrease, leading to lower expenditures in the long term. The latter is significant in an age where budget cuts are the norm for public universities (Mokhta, 2016; MalayMailOnline, 2016). Private universities would also want to increase their profit margins without needless spending on incidents that can be avoided. 


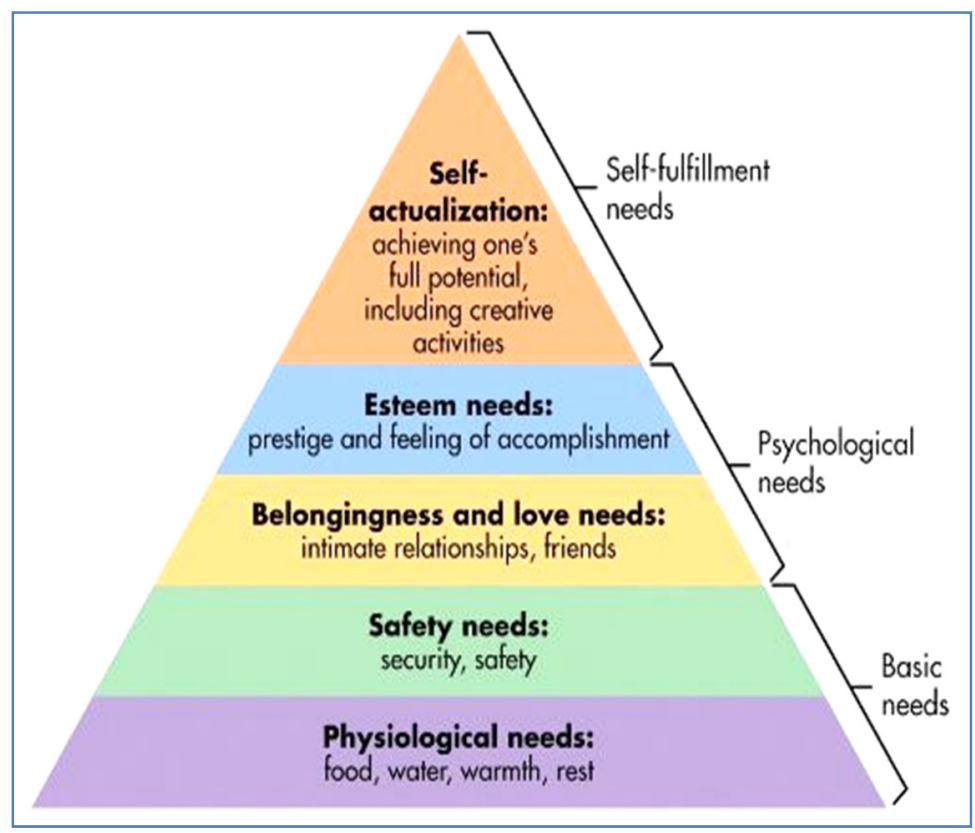

Figure 4. Maslow's Hierarchy of Needs (Source: McLeod, 2016)

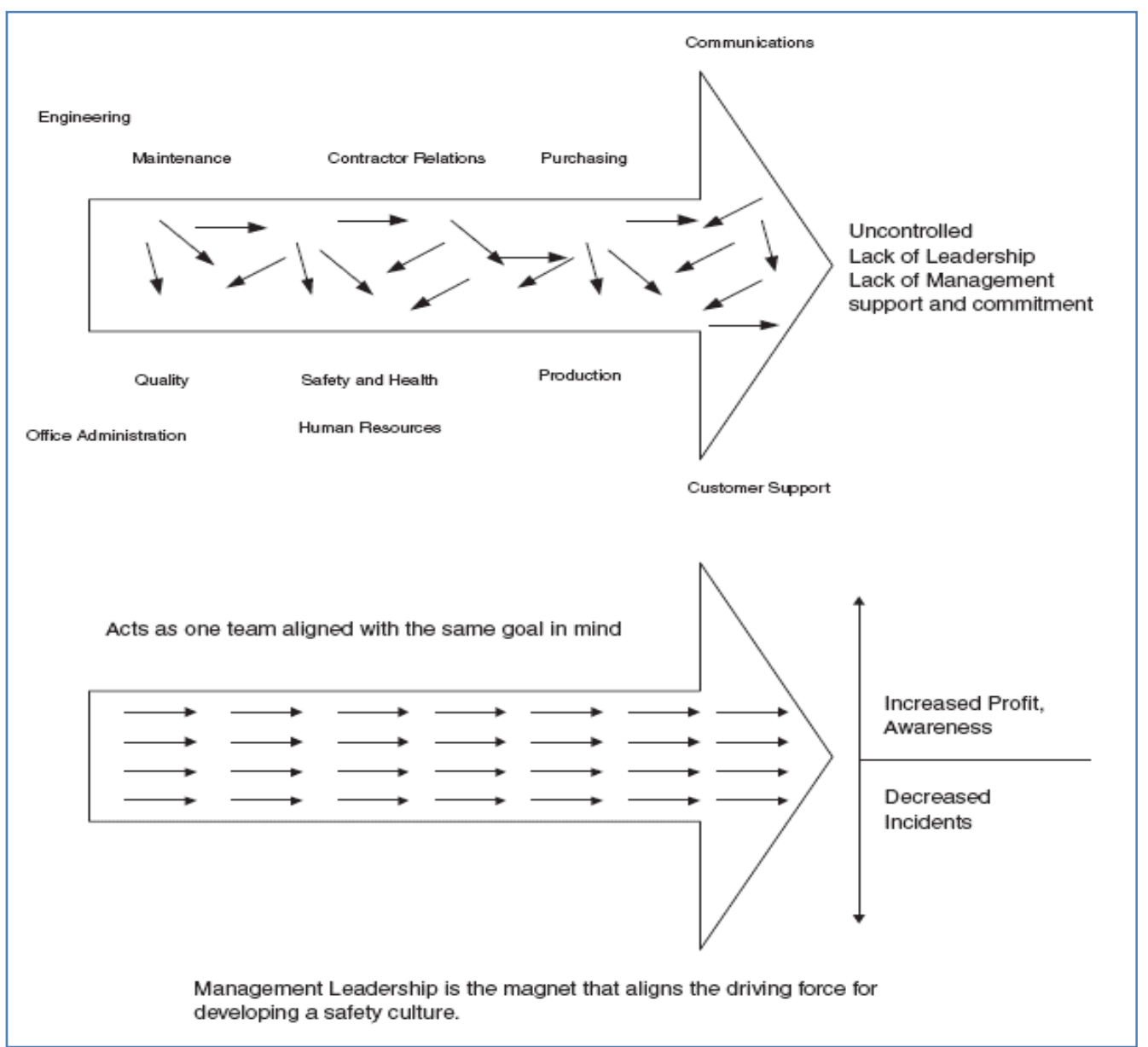

Figure 5. Safety Culture Leadership Model (Source: Roughton and Mercurio, 2002, p. 53) 


\section{Conclusion}

Our survey questionnaire's limitations prevented a comprehensive review of all significant safety matters. The queries were abbreviated as were the survey's duration and sampling. The analytical approach focused only on the present status of both institutions without considering the past. Furthermore, the possibility of 'future improvement' was also beyond the scope of this investigation and the quantitative method employed could not address all possible inferences. However, the surveys provided an effective framework of measurement regarding the importance of management's leadership role as well as a sufficient base that allows a general assessment of current status.

Frequent occurrences of safety incidents are consequent to collective habits, actions and behaviors. Despite the important of safety culture, our findings for both institutions were not encouraging, albeit, they did reflect an early stage of development but with a lack of diligent care on the part of management. None of the areas assessed obtained best practice benchmarks, which is at least a scaled score of 3.0. But what is more alarming, were areas that fell short of passing.

These results strongly suggest that management is far from aligning all parties involved with safety culture within their respective institutions. To achieve this, management should welcome the involvement of all members in their institutional communities rather than adhere to an authoritarian-compliant posture. Safety culture is therefore a collective effort that benefits all parties, especially in cost reductions from proactive hazard reductions. This study lays a foundation for further research that can help us achieve higher standards in institutional settings that are in need of safety culture.

\section{References}

Ahmad, N. (2016, Jan 22). Bomb threat turns out to be a hoax, say police. The Rakyat Post. Retrieved October 27, 2016, from http:/www.therakyatpost.com/news/2016/01/22/bomb-threat-turns-hoax-say-police/

Blewett, V., Rainbird, S., Dorrian, J., Paterson, J., \& Marcus Cattani, M. (2012). Keeping rail on track: preliminary findings on safety culture in Australian rail. Work, 41, 4230-4236.

Bronstein, S., Gaouette, N., Koran, L., \& Ward, C. (2016, September 2016). First on CNN: ISIS planned for more operatives, targets during Paris attacks. CNN. Retrieved October 26, 2016, from http://edition.cnn.com/ 2016/09/05/politics/isis-suspects-terrorism-europe-documents/

Carroll, J. S. (1998). Safety culture as an ongoing process: culture surveys as opportunities for enquiry and change. Work Stress, 12, 272e284.

Christian, M. S., Bradley, J. C., Wallace, J. C., \& Burke, M. J. (2009). Workplace safety: A meta-analysis of the roles of person and situation factors. Journal of Applied Psychology, 94, 1103-1127.

Collins, A. M., \& Gadd, S. (2002). Safety culture: a review of the literature. Sheffield: Health and Safety Laboratory, Human Factors Group.

Collman, A. (2015, September 10). A victim's bloodied flip flops, bullet-pierced soda cups and chilling trails of blood: Never-before-seen evidence photos from inside the movie theater where James Holmes murdered 12 innocent victims. Mail Online. Retrieved October 27, 2016, from http://www.dailymail.co.uk/news/article3229782/Haunting-never-seen-photos-inside-movie-theater-James-Holmes-murdered-12-people-seats-tornshreds-bullet-pierced-soda-cups-trail-blood.html

Cooper, D. (2015). Effective Safety Leadership: Understanding Types \& Styles That Improve Safety Performance. Retrieved September 30, 2016 from www.asse.org

Cooper, M. D. (2000). Towards a model of safety culture. Safety Science, 36, 111-136.

DOSH. (2015). Occupational Accident Statistics. Department of Safety and Health (DOSH). Retrieved from http://www.dosh.gov.my

Dunlap, E. S. (2011). Safety Leadership: Finding Common Ground. Retrieved September 30, 2016, from http://www.dnasafety.net/files/Professional_Safety_Article.pdf

Edwards, J. R. D., Davey, J., \& Armstrong, K. (2013). Returning to the roots of culture: A review and re-conceptualisation of safety culture. Safety Science, 55, 70-80.

Flin, R., \& Yule, S. (2004). Leadership for safety: Industrial experience. QualSaf Health Care, 13, ii45-ii51.

Flin, R., Mearns, K., O‘Connor, P., \& Bryden, R. (2000). Measuring safety climate: Identifying the common features. Safety Science, 34, 177-192. 
Glendon, A. I., \& Stanton, N. A. (2000). Perspectives on safety culture. Safety Science, 34, 193-214.

Guldenmund, F. W. (2000). The nature of safety culture: A review of theory and research. Safety Science, 34(1-3), 215-257.

Guldenmund, F. W. (2010). (Mis) understanding Safety Culture and Its Relationship to Safety Management. Risk Analysis, 30, 1466-1480.

Hamudin, N. (2016, January 22). Bomb scare at local university. The Sun Daily. Retrieved October 27, 2016, from http://www.thesundaily.my/news/1674004

Hudson, P. (2007). Implementing a safety culture in a major multi-national. Safety Science, 45, 697-722.

IOSH. (2015) Promoting a Positive Culture, A Guide to Health and Safety. Institute of Occupational Safety and Health (IOSH). Retrieved October 5, 2016, from http://www.iosh.co.uk/positiveculture

Kumar, K. (2016a, Jan 22). University in Kota Damansara evacuated over bomb scare. Malay Mail Online. Retrieved October 27, 2016, from http://www.themalaymailonline.com/malaysia/article/university-in-kota -damansara-evacuated-over-bomb-scare

Kumar, M. (2016b, July 4). Cops confirm Movida bombing first ever IS attack in Malaysia. The Star Online. Retrieved October 26, 2016, from http://www.thestar.com.my/news/nation/2016/07/04/movida-igp-confirm -is-attack/

Kines, P., Lappalainen, J., Mikkelsen, K. L., Olsen, E., Pousette, A., Tharaldsen, J., Tómasson, K., \& Törner, M. (2011). Nordic safety climate questionnaire (NOSACQ-50): a new tool for measuring occupational safety climate. International Journal of Industrial Ergonomics, 41, 634-646

King L. W. (2008). The Code of Hammurabi. Lillian Goldman Law Library, Yale Law School. Retrieved September 30, 2016, http://avalon.law.yale.edu/ancient/hamframe.asp

Lee, J. (2016, October 10). Breaking: Malaysia University Receives Bomb Threat, Students Immediately Evacuated. World of Buzz. Retrieved October 11, 2016, from http://www.worldofbuzz.com/ breaking-malaysian-university-receives-bomb-threat-students-immediately-evacuated/

Lim, I. (2016, September 30). Police clear Bursa Malaysia of bomb threat, but urge vigilance. Malay Mail Online. Retrieved October 27, 2016, from http://www.themalaymailonline.com/malaysia/article/police-seal-off -bursa-malaysia-over-suspected-bomb-threat

Litherland, D. (1997). Safety Climate: An Investigation of its Underlying Factor Structure and the Relationship with Safety Behaviour. Unpublished paper. School of Applied Psychology, Griffith University, Gold Coast, Queensland.

Lourdes, M. (2016, July 4). Islamic State launches first successful attack in Malaysia. $C N N$. Retrieved October 26, 2016, from http://edition.cnn.com/2016/07/04/homepage2/islamic-state-attack-malaysia/

Lyons, M. (2016). University Safety Culture: A Work-In-Progress? Australian Universities' Review, 58(1), 2016, 45-53.

MalayMailOnline (2016, October 22). Budget 2017: Public universities suffer almost 20pc spending cut. Malay Mail Online. Retrieved October 28, 2016, from http://www.themalaymailonline.com/malaysia/article/budget -2017-public-universities-suffer-almost-20pc-spending-cut

Malaysia (1994). Law of Malaysia. Act 514. Occupational and Health Act 1994.

Maslow, A. H. (1943). A Theory of Human Motivation. Psychological Review, 50(4), 370-96.

McLeod, S. A. (2016). Maslow's Hierarchy of Needs. Retrieved from www.simplypsychology.org/maslow.html

Mohd, H. (2016, June 28). At least six injured in Puchong nightclub attack. New Straits Times Online. Retrieved October 26, 2016, from http://www.nst.com.my/news/2016/06/155179/video-least-six-injured-puchong -nightclub-attack

Mokhta, A. (2016, October 14). Varsities hit hard by budget cuts. New Straits Times Online. Retrieved October 28 , 2016, fromhttp://www.nst.com.my/news/2016/10/180197/varsities-hit-hard-budget-cuts

NST. (March 1, 2016). Important of Safety Audits. New Straits Time Online. Retrieved March 1, 2016, from http://www.nst.com.my/news/2016/03/130354/importance-safety-audits?d=1

O’Connor, P., Buttrey, S, O’Dea, A., \& Kennedy, Q. (2011). Identifying and addressing the limitations of safety climate surveys. Journal of Safety Research, 42, 259-265. 
Othman, A. F. (2016, October 25). Fire erupts at JB's SultanahAminah hospital, six patients killed. New Straits Times Online. Retrieved October 27, 2016, fromhttp://www.nst.com.my/news/2016/10/183163/fire-erupts -jbs-sultanah-aminah-hospital-five-patients-dead

Pearson, M. (2012, July 21). Gunman turns 'Batman' screening into real-life 'horror film'. CNN. Retrieved October 26, 2016, from http://edition.cnn.com/2012/07/20/us/colorado-theater-shooting/

Ramendran, C. (2016, July 4). Puchong bomb attack related to Iocal IS militants: IGP. The Sun Daily. Retrieved October 26, 2016, fromhttp://www.thesundaily.my/news/1876121

Roughton, J. E., \& Mercurio, J. J. (2002). Developing an Effective Safety Culture: A Leadership Approach. Butterworth-Heinemann.

Said, H., \& Othman, A. F. (2016, October 25). Johor hospital blaze: Fire began from ICU treatment room. New Straits Times Online. Retrieved October 26, 2016, from http://www.nst.com.my/news/2016/10/183283/johor -hospital -blaze-fire-began-icu-treatment-room

Silva, J. E. D. (2016, October 10). College bomb hoax snarls up traffic. The Star Online. Retrieved October 11, 2016, fromhttp://www.thestar.com.my/news/nation/2016/10/10/college-bomb-hoax-snarls-up-traffic/

Song, B. M. (2016, September 30). Bursa Malaysia confirms receiving bomb threat. The Sun Daily. Retrieved October 27, 2016, from http://www.thesundaily.my/news/1987987

\section{Copyrights}

Copyright for this article is retained by the author(s), with first publication rights granted to the journal.

This is an open-access article distributed under the terms and conditions of the Creative Commons Attribution license (http://creativecommons.org/licenses/by/4.0/). 